Société d'histoire de la révolution de 1848 et des révolutions du XIXe siècle

$47 \mid 2013$

Quel est l'avenir du XIX $X^{\mathrm{e}}$ siècle ?

\title{
Alain CABANTOUS, Jean-Luc CHAPPEY, Renaud MORIEUX, Nathalie RICHARD et François WALTER [dir.], Mer et montagne dans la culture européenne $\left(\mathrm{XVI}^{e}-\mathrm{XIX} \mathrm{X}^{e}\right.$ siècle)
}

Rennes, Presses universitaires de Rennes, 2011, 281 p. ISBN :

978-2-7535-1279-5. 18 euros.

Karine Salomé

\section{OpenEdition}

Journals

Édition électronique

URL : http://journals.openedition.org/rh19/4629

DOI : $10.4000 /$ rh 19.4629

ISSN : $1777-5329$

Éditeur

La Société de 1848

Édition imprimée

Date de publication : 31 décembre 2013

Pagination : 233-235

ISSN : 1265-1354

Référence électronique

Karine Salomé, «Alain CABANTOUS, Jean-Luc CHAPPEY, Renaud MORIEUX, Nathalie RICHARD et François WALTER [dir.], Mer et montagne dans la culture européenne (XVIe-XIX siècle) », Revue d'histoire du XIXe siècle [En ligne], 47 | 2013, mis en ligne le 28 janvier 2014, consulté le 22 septembre 2020. URL : http://journals.openedition.org/rh19/4629 ; DOI : https://doi.org/10.4000/rh19.4629

Ce document a été généré automatiquement le 22 septembre 2020.

Tous droits réservés 


\section{Alain CABANTOUS, Jean-Luc CHAPPEY, Renaud MORIEUX, Nathalie RICHARD et François WALTER [dir.], Mer et montagne dans la culture européenne (XVI ${ }^{e}-X I X^{e}$ siècle)}

Rennes, Presses universitaires de Rennes, 2011, 281 p. ISBN :

978-2-7535-1279-5. 18 euros.

Karine Salomé

\section{RÉFÉRENCE}

Alain CABANTOUS, Jean-Luc CHAPPEY, Renaud MORIEUX, Nathalie RICHARD et François WALTER [dir.], Mer et montagne dans la culture européenne (XVI ${ }^{e}-X{ }^{e}$ siècle), Rennes, Presses universitaires de Rennes, 2011, 281 p. ISBN : 978-2-7535-1279-5. 18 euros.

L'ouvrage, qui rassemble les communications du colloque organisé à l'université Paris 1 les 24 et 25 septembre 2009, s'inscrit dans la continuité des recherches menées sur les représentations et les usages de la mer et de la montagne. L'originalité de la démarche relève néanmoins de la volonté de confronter ces espaces dans la perspective d'une «histoire sociale de la culture ». Comme le rappellent Alain Cabantous et François Walter dans l'introduction, bien des convergences se dessinent dans la manière dont les sociétés européennes se sont approprié la mer et la montagne. Longtemps perçus comme des éléments indéterminés aux limites incertaines, ces deux espaces témoignent, à l'époque moderne, de l'inachèvement de la nature et constituent des réserves tératologiques, hantées par des dragons et des animaux monstrueux. Érigés au rang de spectacles de la création par les théologies naturelles, ils deviennent 
progressivement des éléments essentiels dans la lecture et la compréhension du monde. Ils font également figure d'espaces insolites, et laissent s'épanouir, dans le même temps, les images de petites républiques égalitaires et libres, à l'existence idyllique et harmonieuse. Enjeux de pouvoir, ils sont l'objet d'une appropriation politique et scientifique par le biais notamment de la cartographie militaire. Au cours du XVIII ${ }^{e}$ siècle s'opère une conversion du regard. Le désir de rivage et de montagne, qui s'accompagne désormais du sentiment du beau et de l'agréable, favorise l'émergence de pratiques touristiques et hygiénistes.

2 Pour autant, les dix-sept communications, dont sept concernent le XIX ${ }^{e}$ siècle, entendent affiner l'analyse et interroger les similitudes et les rapprochements, les spécificités et les différences, autour des thèmes suivants : «l'éclatement des pratiques sociales », « les sciences entre mer et montagne », « représentations et stéréotypes ». Si la mer et la montagne peuvent être unies par des aménagements, en relation par exemple avec l'exploitation du bois à Venise (Andrea Zannini), ces rapports se raréfient, au cours du XIX siècle, au profit d'usages spatiaux différents, parfois concurrents. La construction d'une Provence maritime et d'une Provence des montagnes, à partir de la fin du XVIII ${ }^{\mathrm{e}}$ siècle, accompagne ainsi les profonds bouleversements économiques et sociaux qui voient la déprise agricole et l'industrialisation valoriser le littoral au détriment de la montagne, avant que les deux Provence ne soient érigées au rang d'espaces touristiques et thérapeutiques (Gilbert Buti). L'usage thérapeutique de la mer et de la montagne triomphe en effet au XIX ${ }^{\mathrm{e}}$ siècle. Toutefois, comme le souligne Carole Carribon, les usages et les pratiques se révèlent distincts, les préconisations diffèrent selon l'un ou l'autre espace. De vifs débats opposent d'ailleurs les tenants des vertus maritimes et les partisans des bienfaits du relief. La diversification des usages est perceptible également à travers la comparaison des régates nautiques et des excursions alpinistes proposée par Olivier Hoibian et Denis Jallat. Alors que les régates se partagent entre des individus intéressés par des activités culturelles ou sociales et des adeptes de la performance et de la compétition, les premières sociétés d'alpinistes demeurent favorables à un excursionnisme cultivé et mondain. Dans le domaine des sciences, la mer et la montagne présentent également des divergences. Federico Ferretti met en évidence leur place respective dans la Nouvelle géographie universelle de Reclus. Si la mer et la montagne ont pour fonction de définir et de délimiter l'Europe, elles n'en demeurent pas moins parées de valeurs différentes. Tandis que la montagne, tournée vers le passé, constitue le rempart du continent, la mer permet les échanges et représente une ouverture moderne et contemporaine. L'étude des représentations permet également d'entrevoir les rapports ambivalents qui lient les deux espaces. Jacques Péret relève l'emploi du terme de montagne pour désigner les espaces dunaires situés à l'embouchure de la Gironde. La formule, banale à l'époque moderne, ne survit toutefois, au XIX ${ }^{e}$ siècle, que dans la littérature touristique. Odile Parsis-Barubé propose une belle étude sur la résonnance des deux espaces dans les voyages de Victor Hugo. L'irruption de la montagne apparaît comme une expérience physique, esthétique, méticuleusement consignée, alors que la confrontation avec la mer donne l'impression d'être moins signifiante, d'où une approche plus abstraite de l'espace marin qui se prête alors à maintes transfigurations. En outre, leur rôle dans le déchiffrement de la terre s'oppose. Si la montagne permet, à travers notamment la physionomie des massifs et l'emboîtement de formes identifiables, de s'interroger sur les origines du monde, la mer n'offre que mystère, indécision et évanescence. 
3 L'ouvrage montre ainsi comment les rapports à la mer et à la montagne se construisent de manière parallèle, complémentaire, mais aussi en opposition. Par l'étude conjointe de la place que ces deux espaces occupent dans la culture européenne, il comble un manque et invite à poursuivre la réflexion. 